\title{
Impact of Marijuana Legalization on Opioid Utilization in Patients Diagnosed with Pain
}

\author{
Lynn M. Neilson, $P h D^{7}$, Caroline Swift, PhD, MPH' , Elizabeth C.S. Swart, BS ', \\ Yan Huang, MS', Natasha Parekh, MD, MS $S^{3}$, Kiraat D. Munshi, PhD', \\ Rochelle Henderson, $P h D^{2}$, and Chester B. Good, MD, MPH ${ }^{1,4}$
}

'UPMC Centers for High Value Health Care and Value-Based Pharmacy Initiatives, UPMC Health Plan, Pittsburgh, PA, USA; ${ }^{2}$ Express Scripts, a Cigna subsidiary, St. Louis, MO, USA; ${ }^{3}$ The Queen's Health Systems, affiliated with UPMC Health Plan, Honolulu, HI, USA; ${ }^{4}$ Division of General Internal

Medicine, University of Pittsburgh, Pittsburgh, PA, USA.

BACKGROUND: Given efforts to reduce opioid use, and because marijuana potentially offers a lower-risk alternative for treating chronic pain, there is interest in understanding the public health impact of marijuana legalization on opioid-related outcomes.

OBJECTIVE: Assess the impact of recreational and medical marijuana legalization on opioid utilization among patients receiving pharmacotherapy for pain.

DESIGN: Retrospective claims-based study of commercially insured patients continuously eligible for pharmacy and medical benefits from July 8, 2014 to June 30, 2017. Index pain prescription period was defined between January 8, 2015 and June 30, 2015, and longer-term opioid use examined during 2-year follow-up. Marijuana state policy on July 1, 2015, was assigned: none; medical only; or medical and recreational.

PARTICIPANTS: Patients aged 18-62 without cancer diagnosis.

MAIN MEASURES: Patient receiving (1) opioid at index; (2) > 7 days' supply of index opioid; (3) opioid during follow-up; and (4) $\geq 90$ days' opioid supply during follow-up. Multivariable regression assessed associations between opioid utilization and state marijuana policy, adjusting for age, gender, overall disease burden, mental health treatment, concomitant use of benzodiazepine or muscle relaxant, and previous pain prescription.

KEY RESULTS: Of 141,711 patients, 80,955 (57.1\%) resided in states with no policy; 56,494 (39.9\%) with medical-only; and 4262 (3.0\%) with medical and recreational. Patients in states with both policies were more likely to receive an index opioid $(\mathrm{aOR}=1.72,95 \% \mathrm{CI}=$ $1.61-1.85 ; \mathrm{aOR}=1.90,95 \% \mathrm{CI}=1.77-2.03 ; P<0.001)$ but less likely to receive $>7$ days' index supply $(\mathrm{aOR}=$ $0.84,95 \% \mathrm{CI}=0.77-0.91$; $\mathrm{aOR}=0.76,95 \% \mathrm{CI}=0.70$ 0.83; $P<0.001$ ) than patients in states with no policy or medical-only, respectively. Those in states with both policies were more likely to receive a follow-up opioid $(\mathrm{aOR}=$ $1.87,95 \% \mathrm{CI}=1.71-2.05 ; \mathrm{aOR}=2.20,95 \% \mathrm{CI}=2.01-$ 2.42; $P<0.001$ ) than those in states with no policy or medical-only, respectively, and more likely to receive $\geq$

This work was presented as a poster at the AcademyHealth 2020 Annual (Virtual) Research Meeting on July 28-August 6, 2020.

Received September 16, 2020

Accepted December 20, 2020

Published online February 11, 2021
90 cumulative follow-up opioid days' supply (aOR = $1.18,95 \% \mathrm{CI}=1.07-1.29 ; P<0.001)$ than those in states with no policy.

CONCLUSIONS: Our analysis does not support the supposition that access to marijuana lowers use of chronic opioids for pain.

KEY WORDS: pain; opioids; marijuana; policy.

J Gen Intern Med 36(11):3417-22

DOI: $10.1007 / \mathrm{s} 11606-020-06530-6$

(c) Society of General Internal Medicine 2021

\section{INTRODUCTION}

The alarming rates of opioid use and opioid-related deaths over the past several decades in the USA have resulted in a nationwide public health crisis. ${ }^{1,2}$ The annual number of overdose deaths involving opioids has risen sharply, from 18,515 deaths in 2007 to 67,367 deaths in $2018 .^{3}$ In addition to overdose mortality, opioid misuse and abuse has been associated with a surge in emergency room visits ${ }^{2,4}$ and inpatient admissions. ${ }^{5,6}$ Concurrently over the past several decades, many states have legalized marijuana, either recreationally, medically, or both. At the time of publication, comprehensive medical marijuana programs have been legally approved in 33 states and Washington, DC, and adult-use recreational marijuana has been legalized in 11 states and Washington, DC. ${ }^{7-9}$ Given the ongoing efforts to reduce opioid prescribing and use, and because marijuana potentially offers a non-opioid alternative for the treatment of chronic pain ${ }^{10}$ with a potentially lower risk of addiction and essentially no risk of overdose, there has been increased interest in understanding the public health impact of marijuana legalization on opioid-related outcomes.

It should be noted that there are many potential indications for medical marijuana, which vary from state to state. For example, the state of Pennsylvania lists 23 qualifying conditions for its medical marijuana program, including "severe chronic or intractable pain of neuropathic origin or severe chronic or intractable pain." 11 Despite widespread use of 
marijuana for chronic pain, there is insufficient evidence that marijuana is safe and effective for this indication. ${ }^{12}$

Studies exploring the relationship between marijuana and opioid use have shown mixed results. While some studies suggest that medical and recreational marijuana legalization can reduce risk of opioid overdose mortality, ${ }^{13,14}$ others suggest that marijuana use may be a "gateway drug"15 and is associated with increased opioid use and development of opioid use disorder. ${ }^{16,17}$ Furthermore, while studies suggest that marijuana legalization can lead to reduced opioid prescribing, ${ }^{18-20}$ hospitalizations for opioid overdoses, ${ }^{21}$ and utilization of certain other prescription drugs, ${ }^{22}$ the impact of marijuana legalization on opioid utilization patterns is unclear, especially as it relates to factors at the patient level.

Unlike previous studies, the current analysis focused on initial prescription and long-term opioid utilization in patients with pain diagnoses who reside in states with no marijuana policy, medical marijuana only policy, or medical and recreational marijuana policies, and adjusts for patient-level factors including age, gender, overall disease burden, mental health treatment, concomitant use of benzodiazepine or muscle relaxant, and previous pain prescription. The goal of this study was to assess the impact of recreational and medical marijuana legalization on opioid utilization among patients receiving treatment for pain.

\section{METHODS}

\section{Study Population}

This study used prescription claims from a commercially insured population whose pharmacy benefits were managed by a large national pharmacy benefit management company. Inclusion was limited to patients who were continuously eligible for pharmacy and medical benefits from July 8, 2014 to June 30, 2017, who were aged 1862 as of their index pain prescription, and who had no cancer diagnosis over the study period. Index pain medication was identified as a pain prescription within the index period between January 8, 2015 and June 30, 2015. All pharmacy pain claims within $96 \mathrm{~h}$ of the first recorded index pain prescription were counted as index pain medications, and this $96-\mathrm{h}$ window allowed for identifying the pain-related medical claim associated with the index pain prescription. We excluded patients with invalid or incomplete data for morphine equivalent dose, medical or pharmacy claims, or geographic region.

\section{Study Variables}

The primary outcomes were measured at the patient level and included whether the patient's index pain prescription contained an opioid, whether the patient ever received an opioid during the 2-year follow-up period, whether the patient received $>7$ days' supply of opioid medication at index, and/or whether they received $\geq 90$ days' supply of opioids during the 2year follow-up period. Secondary outcomes included index prescription mean days' supply of opioid medication and index prescription mean daily morphine equivalent dose (MED). Morphine equivalent dose was defined as the sum of milligram morphine equivalent (MME), calculated as a daily amount based on prescribing information. ${ }^{23}$ State policy was assigned to the patient based on their address on the index claim; states were categorized based on the state marijuana policy status on July 1, 2015, where 1, no marijuana policy; 2 , medical marijuana policy; and 3 , medical and recreational marijuana policy. The index period and July 1, 2015 , policy date were chosen due to the limited number of state marijuana policy changes enacted during this time frame. Age was documented as the patient's age on the date of index prescription claim. Region was defined as the US Census region associated with the patient's zip code on the date of index prescription claim. Newly prescribed pain treatment was defined as having no prescription claim in the 180 days prior to the index pain prescription for gamma-aminobutyric acid (GABA) analogues, opioids, NSAIDs, acetaminophen, or combination therapy using these types of medications (e.g., hydrocodone with acetaminophen). Out-of-state pharmacy and out-of-state prescriber variables indicate whether the patient filled the prescription in a pharmacy outside the patient's state of residence or the prescriber was licensed outside the patient's state of residence. Indicator variables for index period benzodiazepine and muscle relaxant were defined as the patient having at least one prescription claim for a benzodiazepine or muscle relaxant in the index period. Overall disease burden was defined as the count of unique 2-digit generic product identifiers (GPIs), which indicated the number of disease conditions for which patient was being treated during the 2-year follow-up period. ${ }^{24} \mathrm{Men}$ tal health treatment indicator variable was defined as patients having at least one prescription claim or medical claim with a diagnosis code for depression, anxiety, substance abuse, or alcohol treatment in the 2-year follow-up period.

\section{Statistical Analysis}

We conducted a retrospective study of claims data, using multivariable logistic regression models to assess associations between opioid utilization and state marijuana policy, adjusting for age, gender, overall disease burden, mental health treatment, concomitant medication use in the index period for benzodiazepine or muscle relaxant, and previous pain treatment. Descriptive 
statistics were estimated and bivariate relationships were tested using Kruskal-Wallis (non-parametric) with post hoc analyses using Bonferroni Dunn $T$ tests for continuous variables and chi-square tests for categorical variables. All analyses were conducted using SAS Enterprise Guide version 9.4 (SAS Institute, Cary, NC).

\section{RESULTS}

From a population of more than 31 million commercially insured members, we identified 305,054 patients that filled an index pain medication prescription. Figure 1 presents the sample selection criteria for the study, which resulted in 141,711 being selected for the final analytical sample.

Of the 141,711 patients in the study, 80,955 (57.1\%) resided in states with no marijuana policy at the time of index prescription; $56,494(39.9 \%)$ resided in states with only a medical marijuana policy at index; and 4262 (3.0\%) resided in states with both a medical and recreational marijuana policy at index (Table 1). Female patients accounted for $56.6 \%, 55.6 \%$, and $57.5 \%$ of each group, respectively, and patients aged 45-62 years accounted for $59.5 \%, 59.5 \%$, and $59.2 \%$ of each group, respectively. Geographically, the largest representation by region varied by policy: $98.9 \%$ of patients with both medical and recreational policies at the time of their index pain claim resided in the West, whereas 59.2\% of patients who resided in states with no marijuana policies were from the South.

Among all policy groups, patient's disease burden ranged from 9 to 10.1, indicating that on average patients had medications to treat between 9 and 10 various conditions. Patients

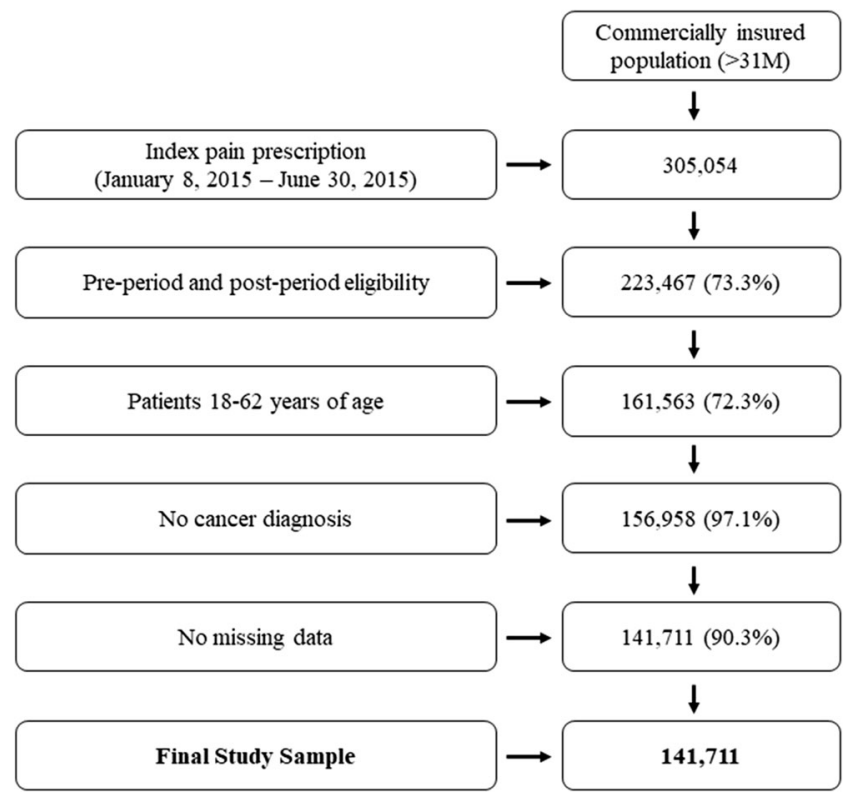

Figure 1 Sample selection criteria flow chart, $N(\%)$ retained. residing in states with no marijuana policy at index had the highest number of comorbidities and a slightly higher proportion of being prescribed a medication for a mental health condition. All of the assessed variables in Table 1 varied significantly by marijuana policy type, except in a few cases where indicated.

Table 2 presents the unadjusted rates that prescribing patterns differ between those residing in states with medical and recreational marijuana policies, those residing in states with only a medical marijuana policy, and those residing in states with no policy. Patients in the medical and recreational policy states had higher rates of opioids prescribed as index medication $(70 \%$ vs. $59.2 \%$ and $57.2 \%, P<0.001)$ and higher rates of opioids prescribed in the follow-up period $(86.4 \%$ vs. $80.1 \%$ and $75.7 \%, P<0.001)$. Among patients that received an opioid at the time of index $(n=83,252)$, those in states with both medical and recreational marijuana policies were less likely to be prescribed more than 7 days' supply at index (33.4\% vs. $37.6 \%$ and $37.7 \%, P<0.001)$ but had a larger mean daily MED for index medication (59.5 vs. 48.7 and 51.9, $P<0.001$ ). There was no significant difference in the mean index opioid days' supply filled by marijuana policy.

Table 3 shows the multivariable analysis findings that tested the effect of different marijuana policies and other covariates on opioid prescribing and utilization outcomes. Consistent with univariate analyses, patients living in states with medical and recreational policies were significantly more likely to be prescribed an opioid as one of the index medications $(\mathrm{aOR}=1.72,95 \% \mathrm{CI}=1.61-1.85$; $\mathrm{aOR}=1.90,95 \% \mathrm{CI}=1.77-2.03 ; P<0.001)$ but less likely to be prescribed more than a 7 days' supply of opioids for their index medication $(\mathrm{aOR}=0.84,95 \% \mathrm{CI}$ $=0.77-0.91 ; \mathrm{aOR}=0.76,95 \% \mathrm{CI}=0.70-0.83 ; P<$ 0.001 ) compared to patients living in states with no marijuana policy or a medical marijuana only policy, respectively. Those living in states with medical and recreational policies were also more likely to receive an opioid prescription in the 2-year period following their index claim $(\mathrm{aOR}=1.87,95 \% \mathrm{CI}=1.71-2.05 ; \mathrm{aOR}=2.20,95 \% \mathrm{CI}=$ $2.01-2.42 ; P<0.001)$ compared to those living in states with no marijuana policy or a medical marijuana only policy, respectively, and more likely to be prescribed $\geq$ 90 cumulative days' supply of opioids in the follow-up period $(\mathrm{aOR}=1.18,95 \% \mathrm{CI}=1.07-1.29 ; P<0.001)$ than those living in states with no marijuana policy. Patients living in states with a medical marijuana only policy were less likely to be prescribed an opioid as one of the index medications (aOR 0.91, 95\% CI $=0.89-0.93 ; P<0.001$ ) or in the follow-up period $(\mathrm{aOR}=0.85,95 \% \mathrm{CI}=0.83$ $0.87 ; P<0.001)$, but more likely to be prescribed $>7$ days' supply at index $(\mathrm{aOR}=1.10,95 \% \mathrm{CI}=1.07-1.14$; $P<0.001)$ and $\geq 90$ cumulative days' supply of opioids in the follow-up period $(\mathrm{aOR}=1.16,95 \% \mathrm{CI}=1.12-1.21 ; P$ $<0.001$ ) compared to those residing in states with no marijuana policy. 
Table 1 Population Characteristics, $n=141,711^{*}$

\begin{tabular}{|c|c|c|c|c|}
\hline & \multicolumn{3}{|l|}{$n(\%)$ or mean (SD) } & \multirow[t]{2}{*}{$P$ value } \\
\hline & $\begin{array}{l}\text { No marijuana policy } \\
\text { at index, } n=80,955 \\
(57.1 \%)\end{array}$ & $\begin{array}{l}\text { Medical marijuana policy } \\
\text { only at index, } n=56,494 \\
(39.9 \%)\end{array}$ & $\begin{array}{l}\text { Medical and recreational } \\
\text { marijuana policy at index, } \\
n=4,262(3.0 \%)\end{array}$ & \\
\hline \multicolumn{5}{|l|}{ Demographic information } \\
\hline \multicolumn{5}{|l|}{ Gender } \\
\hline Female & $45,851(56.6 \%)$ & $31,422(55.6 \%)$ & $2451(57.5 \%)$ & $<0.001$ \\
\hline Mean age (years) (SD) & $45.8(12.2)$ & $45.5(12.1)$ & $45.8(12.3)^{\dagger}$ & $<0.001$ \\
\hline Age group $(\%)$ & & & & $<0.001$ \\
\hline $18-24$ years & $6669(8.2 \%)$ & $4795(8.5 \%)$ & $340(8.0 \%)$ & \\
\hline $25-34$ years & $9544(11.8 \%)$ & $6504(11.5 \%)$ & $545(12.8 \%)$ & \\
\hline $35-44$ years & $16,528(20.4 \%)$ & $11,671(20.7 \%)$ & $854(20.0 \%)$ & \\
\hline $45-54$ years & $23,340(28.8 \%)$ & $17,486(31.1 \%)$ & $1190(27.9 \%)$ & \\
\hline $55-62$ years & $24,874(30.7 \%)$ & $16,028(28.4 \%)$ & $1333(31.3 \%)$ & \\
\hline \multicolumn{4}{|l|}{ Region } & $<0.001$ \\
\hline Northeast & $4170(5.2 \%)$ & $23,025(40.8 \%)$ & $0(0.0 \%)$ & \\
\hline Midwest & $27,255(33.7 \%)$ & $9574(17.0 \%)$ & $0(0.0 \%)$ & \\
\hline South & $47,920(59.2 \%)$ & $3200(5.7 \%)$ & $48(1.1 \%)$ & \\
\hline West & $1610(2.0 \%)$ & $20,695(36.6 \%)$ & $4214(98.9 \%)$ & \\
\hline New prescription pain treatment & $48,217(59.6 \%)$ & $36,188(64.1 \%)$ & $2580(60.5 \%)$ & $<0.001$ \\
\hline \multicolumn{5}{|c|}{ Index pain prescription pharmacy information } \\
\hline Pharmacy out of state & $10,056(12.4 \%)$ & $5622(10.0 \%)$ & $728(17.1 \%)$ & $<0.001$ \\
\hline Prescriber out of state & $11,215(13.9 \%)$ & $7639(13.5 \%)$ & $749(17.6 \%)$ & $<0.001$ \\
\hline Benzodiazepine: index period & $1188(1.5 \%)$ & $794(1.4 \%)$ & $91(2.1 \%)$ & $<0.001$ \\
\hline Benzodiazepine: post period & $9210(11.4 \%)$ & $5977(10.6 \%)$ & $598(14.0 \%)$ & $<0.001$ \\
\hline Muscle relaxant: index period & $8430(10.4 \%)$ & $5306(9.4 \%)$ & $387(9.1 \%)$ & $<0.001$ \\
\hline Muscle relaxant: post period & $28,135(34.8 \%)$ & $16,513(29.2 \%)$ & $1410(33.1 \%)$ & $<0.001$ \\
\hline \multicolumn{5}{|c|}{ Disease burden-unique GPI- 2 count } \\
\hline Mean disease burden (SD) & $10.1(5.4)$ & $9.0(5.0)^{\ddagger}$ & $9.1(5.2)^{\S}$ & $<0.001$ \\
\hline $\begin{array}{l}\text { Mental health treatment } \\
\text { indicator }\end{array}$ & $31,922(39.4 \%)$ & $19,889(35.2 \%)$ & $1671(39.2 \%)$ & $<0.001$ \\
\hline
\end{tabular}

*All data were statistically significant at the $P<0.001$ across groups, except for cells marked with a note indicating otherwise. Region is based on US Census regions. Disease burden was defined as a unique count of 2-digit GPIs used by the patient, indicating the number of unique drug groups for which the patient had a prescription claim in the study period. Mental health treatment indicator was defined as having a prescription claim for a mental health medication or medical claim with a diagnosis code for any mental health condition in the follow-up period

+Not significantly different from no marijuana policy or from medical marijuana policy only at index

Not significantly different from medical and recreational marijuana policy at index

${ }^{s_{N}}$ Not significantly different from medical marijuana policy only at index

GPI generic product identifier, OOP out-of-pocket, SD standard deviation

Table 2 Descriptive Opioid Utilization Patterns by State Policy Status*

\begin{tabular}{|c|c|c|c|c|}
\hline \multirow[b]{2}{*}{ State policy status } & \multicolumn{3}{|l|}{$n(\%)$ or mean (SD) } & \multirow[t]{2}{*}{$P$ value } \\
\hline & $\begin{array}{l}\text { No marijuana policy } \\
\text { at index }\end{array}$ & $\begin{array}{l}\text { Medical marijuana policy } \\
\text { only at index }\end{array}$ & $\begin{array}{l}\text { Medical and recreational } \\
\text { marijuana policy at index }\end{array}$ & \\
\hline Among entire sample $(n=141,711)$ & $n=80,955$ & $n=56,494$ & $n=4262$ & \\
\hline Opioid index prescription & $47,946(59.2 \%)$ & $32,323(57.2 \%)$ & $2983(70.0 \%)$ & $<0.001$ \\
\hline Follow-up opioid prescription & $64,865(80.1 \%)$ & $42,755(75.7 \%)$ & $3683(86.4 \%)$ & $<0.001$ \\
\hline $\begin{array}{l}\text { Among those with new pain } \\
\text { prescriptions }(n=86,985)\end{array}$ & $n=48,217$ & $n=36,188$ & $n=2580$ & \\
\hline Opioid index prescription & $29,455(61.1 \%)$ & $20,646(57.1 \%)$ & $1868(72.4 \%)$ & $<0.001$ \\
\hline $\begin{array}{l}\text { Among those prescribed opioids at } \\
\text { index }(n=83,252)\end{array}$ & $n=47,946$ & $n=32,323$ & $n=2983$ & \\
\hline Index opioid days' supply $>7$ & $18,044(37.6 \%)$ & $12,171(37.7 \%)$ & $995(33.4 \%)$ & $<0.001$ \\
\hline Cumulative days' supply $\geq 90$ & $1935(4.0 \%)$ & $1269(2.5 \%)$ & $102(4.0 \%)$ & $<0.001$ \\
\hline Mean daily index MED ( $\overline{\mathrm{SD}})$ & $48.7(70.2)$ & $51.9(90.5)$ & $59.5(89.5)$ & $<0.001$ \\
\hline $\begin{array}{l}\text { Mean index opioid days' supply } \\
\text { (SD) }\end{array}$ & $11.3(14.1)^{\dagger}$ & $11.3(13.9)^{\dagger}$ & $10.9(15.1)^{\dagger}$ & NS \\
\hline
\end{tabular}

*All data were statistically significant at the $P<0.001$ across groups, except for cells marked with a note indicating otherwise

†Not significantly different across groups

Follow-up opioid defined as any opioid prescription within the 2-year follow-up period. SD standard deviation, MED morphine equivalent dose, NS not significant 
Table 3 Multivariable Analysis of Opioid Utilization by State Marijuana Policy

\begin{tabular}{|c|c|c|c|c|}
\hline & $\begin{array}{l}\text { Opioid index Rx, } \\
n=83,252\end{array}$ & $\begin{array}{l}\text { Follow-up opioid Rx, } \\
n=111,303\end{array}$ & $\begin{array}{l}\text { Index opioid prescription } \\
\text { days' supply }>7, n=\mathbf{3 1 , 2 1 0}\end{array}$ & $\begin{array}{l}\text { Follow-up cumulative opioid } \\
\text { days' supply } \geq 90, n=\mathbf{3 3 0 6}\end{array}$ \\
\hline Parameter & $\begin{array}{l}\text { Adjusted odds ratio } \\
\text { estimate (95\% Wald } \\
\text { CI) }\end{array}$ & $\begin{array}{l}\text { Adjusted odds ratio } \\
\text { estimate }(95 \% \text { Wald } \\
\text { CI) }\end{array}$ & $\begin{array}{l}\text { Adjusted odds ratio } \\
\text { estimate (95\% Wald CI) }\end{array}$ & $\begin{array}{l}\text { Adjusted odds ratio estimate } \\
\text { (95\% Wald CI) }\end{array}$ \\
\hline \multicolumn{5}{|l|}{ Marijuana policy at index } \\
\hline $\begin{array}{l}\text { Medical+recreational vs. } \\
\text { medical }\end{array}$ & $1.90(1.77-2.03) *$ & $2.20(2.01-2.42) *$ & $0.76(0.70-0.83) *$ & $1.01(0.92-1.12)$ \\
\hline $\begin{array}{l}\text { Medical+recreational vs. } \\
\text { none }\end{array}$ & $1.72(1.61-1.85) *$ & $1.87(1.71-2.05) *$ & $0.84(0.77-0.91) *$ & $1.18(1.07-1.29) *$ \\
\hline Medical vs. none & $0.91(0.89-0.93) *$ & $0.85(0.83-0.87) *$ & $1.10(1.07-1.14) *$ & $1.16(1.12-1.21) *$ \\
\hline Age & $0.99(0.99-0.99) *$ & $0.99(0.99-0.99) *$ & $1.03(1.03-1.03) *$ & $1.03(1.02-1.03) *$ \\
\hline Female gender & $0.89(0.87-0.91) *$ & $0.82(0.80-0.84) *$ & $0.83(0.80-0.85) *$ & $0.74(0.71-0.76) *$ \\
\hline $\begin{array}{l}\text { No previous pain } \mathrm{Rx} \text { before } \\
\text { index }\end{array}$ & $1.04(1.02-1.07) *$ & $0.87(0.84-0.89) *$ & $0.20(0.19-0.21) *$ & $0.09(0.08-0.09) *$ \\
\hline $\begin{array}{l}\text { Out-of-state pharmacy at } \\
\text { index }\end{array}$ & $0.29(0.28-0.30) *$ & $0.42(0.40-0.43) *$ & $1.69(1.57-1.81) *$ & $0.82(0.78-0.87) *$ \\
\hline $\begin{array}{l}\text { Out-of-state prescriber at } \\
\text { index }\end{array}$ & $1.96(1.89-2.03) *$ & $1.67(1.60-1.75) *$ & $0.64(0.61-0.68) *$ & $0.87(0.82-0.92) *$ \\
\hline $\begin{array}{l}\text { Benzodiazepine: index } \\
\text { period }\end{array}$ & $1.43(1.30-1.57) *$ & $1.26(1.19-1.32) *$ & $1.76(1.56-1.99) *$ & $1.63(1.56-1.71) *$ \\
\hline $\begin{array}{l}\text { Muscle relaxant: index } \\
\text { period }\end{array}$ & $0.73(0.71-0.76) *$ & $1.11(1.07-1.14) *$ & $1.72(1.63-1.81) *$ & $2.16(2.09-2.24) *$ \\
\hline $\begin{array}{l}\text { Disease burden-unique } \\
\text { GPI- } 2 \text { count }\end{array}$ & $1.02(1.02-1.02) *$ & $1.14(1.14-1.15) *$ & $1.03(1.02-1.03) *$ & $1.04(1.03-1.04) *$ \\
\hline $\begin{array}{l}\text { Mental health treatment } \\
\text { indicator }\end{array}$ & $1.24(1.21-1.27) *$ & $1.15(1.12-1.19) *$ & $1.30(1.26-1.35) *$ & $1.90(1.84-1.98) *$ \\
\hline
\end{tabular}

$* P<0.001$. Rx prescription, GPI generic product identifier, CI confidence interval

\section{DISCUSSION}

This study seeks to fill gaps in the current literature surrounding the association of marijuana policy presence on opioid utilization patterns at the patient level. Unlike previous population-based studies ${ }^{18,19}$, this analysis focused on initial prescription and long-term opioid utilization in patients with pain diagnoses. Overall, our analysis suggests that marijuana policies have a complex relationship with opioid utilization. Among patients receiving pharmacotherapy after presenting with pain, we found that those residing in states with access to recreational and medical marijuana have higher rates of both initial and longer-term opioid use. However, among patients in states with only medical marijuana access, both initial and longer-term opioid use is less likely than for those residing in states with medical and recreational laws or no marijuana policy at all. Because initial use of opioids in our study may potentially reflect prescribing for acute pain, which we are unable to distinguish from initial opioid use for the treatment of chronic pain in our analyses, and for which there is no indication that marijuana is an effective alternative treatment, perhaps the most relevant measures of the influence of marijuana policies on opioid use are measures within the 2-year follow-up period. Notably, patients living in states with medical and recreational marijuana policies were more likely to receive $\geq 90$ cumulative days' supply of opioids in the followup period than those living in states with no marijuana policy.

In general, our findings are not consistent with previous studies that were performed at a population level, which largely demonstrate an inverse relationship between enacted state marijuana policies and rates of opioid prescribing and use. ${ }^{18,19}$ For example, a study of Medicaid enrollees found that implementation of medical and/or recreational marijuana laws between 2011 and 2016 resulted in a lower rate of opioid prescribing. ${ }^{18}$ However, this analysis examined the overall number of state-level opioid prescriptions and did not adjust for patient-level variables known to influence opioid prescribing patterns, or take into account variations in dosage. Similarly, an aggregate study was conducted in a Medicare Part D population, which concluded that medical marijuana legalization was associated with a lower odds of opioid use as measured by the total number of state-wide daily doses prescribed per year. ${ }^{19}$ One study that was more closely related to ours examined the impact of medical marijuana legalization on opioid prescribing in a commercially insured population, adjusting for patient-level factors such as age, gender, and pain diagnosis. ${ }^{20}$ This report concluded that opioid prescribing was modestly lower in states with a medical marijuana policy enacted by December 2014, but did not take into account recreational marijuana policies. ${ }^{20}$ The differences in our findings may be due to the distinct and divergent way in which states were categorized into comparison groups within each study, as well as the differing timeframes examined and potentially differences in patient populations.

Our study has some limitations. Most importantly, our results are observational and utilize claims data only. Although we attempted to adjust for all relevant confounders available in our models, it is possible that other important unmeasured confounders were not addressed. Second, as mentioned above, we were unable to delineate whether index opioid was prescribed to treat acute or chronic pain. Third, 
during the 2-year follow-up period, some states had changes in marijuana policies, and we were not able to adjust for those changes given the nature of our patient-level analysis. It is possible that members and/or prescribers in states with recreational and/or medical marijuana laws had more permissive attitudes towards use of prescription opioids during the time of study. Fourth, use of over-the-counter pain medications that were not processed through the patient's pharmacy or medical benefits were not captured in this study. Furthermore, as is the case in other studies examining state marijuana policies and subsequent opioid prescribing, we do not know if patients in our study used recreational or medical marijuana to manage either acute or chronic pain. Finally, it is important to note that even though our study period is recent, there have been rapid changes in attitudes and practices for prescribing opioids for acute and chronic pain. Further analyses are needed to assess the interaction of changing policies and prescribing patterns for opioids, especially as they relate to opioid days' supply and dose limits, prescription drug monitoring programs, and private benefit policies that may influence opioid utilization over time.

Our study adds to the literature on the association of state marijuana laws and use of prescription opioids for the treatment of pain. Our study casts doubt that at the patient level, recreational access to marijuana is associated with reduced opioid utilization. Perhaps most importantly, our study does not support the supposition that access to marijuana (medically or for recreation) lowers use of chronic opioids for pain.

Acknowledgments: This work was supported by Express Scripts Holding Company.

Corresponding Author: Lynn M. Neilson, PhD; UPMC Centers for High Value Health Care and Value-Based Pharmacy Initiatives, UPMC Health Plan, Pittsburgh, PA, USA (e-mail: neilsonl@upmc.edu).

\section{Compliance with Ethical Standards:}

Conflict of Interest: Authors LN, ES, YH, NP, and CG are or were employed by UPMC at the time that research was conducted, and CS, $\mathrm{KM}$, and RH are or were employed by Express Scripts Holding Company at the time that research was conducted.

\section{REFERENCES}

1. Rudd RA, Aleshire N, Zibbell JE, Gladden RM. Increases in Drug and Opioid Overdose Deaths - United States, 2000-2014. Centers for Disease Control and Prevention Morb Mortal Wkly Rep 2016;64(50-51):1378-82.

2. Salzman M, Jones CW, Rafeg R, Gaughan J, Haroz R. Epidemiology of Opioid-related Visits to US Emergency Departments, 1999-2013: A Retrospective Study from the National Hospital Ambulatory Medical Care Survey. Am J Emerg Med 2019. [Epub ahead of print].
3. CDC WONDER. https://www.drugabuse.gov/related-topics/trends-statistics/overdose-death-rates. Accessed on Mar 29, 2020

4. Hasegawa K, Espinola JA, Brown DF, Camargo CA Jr. Trends in U.S. Emergency Department Visits for Opioid Overdose, 1993-2010. Pain Med 2014;15(10):1765-70.

5. Ronan MV and Herzig SJ. Hospitalizations Related To Opioid Abuse/ Dependence And Associated Serious Infections Increased Sharply, 200212. Health Aff (Millwood) 2016;35(5):832-7.

6. Unick GJ, Rosenblum D, Mars S, Ciccarone D. Intertwined Epidemics: National Demographic Trends in Hospitalizations for Heroin- and Opioidrelated Overdoses, 1993-2009. PLoS One 2013;8(2):e54496.

7. DISA Global Solutions. Map of Marijuana Legality by State. https://disa. com/map-of-marijuana-legality-by-state. Accessed on Mar 29, 2020.

8. National Conference of State Legislatures. State Medical Marijuana Laws. https://www.ncsl.org/research/health/state-medical-marijuana-laws. aspx. Accessed Apr 13, 2020.

9. Marijuana Policy Project. 2020 Marijuana Policy Reform Legislation. https://www.mpp.org/issues/legislation/key-marijuana-policy-reform/. Accessed Apr 13, 2020.

10. National Academies of Sciences, Engineering, and Medicine. The Health Effects of Cannabis and Cannabinoids: The Current State of Evidence and Recommendations for Research. National Academies Press: Washington, DC, 2017.

11. Commonwealth of Pennsylvania Medical Marijuana Program. https:// www.pa.gov/guides/pennsylvania-medical-marijuana-program/. Accessed Nov 13, 2020.

12. Nugent et al: The effects of cannabis among adults with chronic pain and an overview of general harms: a systematic review. Ann Intern Med 2017; 167:319-331.

13. Bacchuber MA, Saloner B, Cunningham Co, et al. Medical Cannabis Laws and Opioid Analgesic Overdose Mortality in the United States, 1999-2010. JAMA Intern Med 2014;174(10):1668-1673.

14. Livingston MD, Barnett TE, Delcher C, Wagenaar AC. Recreational Cannabis Legalization and Opioid-Related Deaths in Colorado, 20002015. Am J Public Health 2017; 107(11): p. 1827-1829.

15. National Institute on Drug Abuse. Is Marijuana a Gateway Drug? https://www.drugabuse.gov/publications/research-reports/marijuana/ marijuana-gateway-drug. Accessed Jan 15, 2020.

16. Olfson M, Wall MM, Liu S-M, Blanco C. Cannabis Use and Risk of Prescription Opioid Use Disorder in the United States. Am J Psychiatr 2018;175(1): 47-53.

17. Lynskey MT, Heath AC, Bucholz KK, et al. Escalation of Drug Use in Early-onset Cannabis Users versus Co-twin Controls. JAMA. 2003;289(4):427-433.

18. Wen $\mathbf{H}$ and Hockenberry JM. Association of Medical and Adult-Use Marijuana Laws with Opioid Prescribing for Medicaid Enrollees. JAMA Intern Med 2018;178(5):673-679.

19. Bradford AC, Bradford WD, Abraham A, Bagwell Adams G. Association Between US State Medical Cannabis Laws and Opioid Prescribing in the Medicare Part D Population. JAMA Intern Med 2018;178(5):667-672.

20. Shah A, Hayes CJ, Lakkad M, Martin BC. Impact of Medical Marijuana Legalization on Opioid Use, Chronic Opioid Use, and High-risk Opioid Use. J Gen Intern Med 2019;34(8):1419-1426.

21. Shi Y. Medical marijuana policies and hospitalizations related to marijuana and opioid pain reliever. Drug Alcohol Depend 2017;173:144-150.

22. Bradford AC and Bradford WD. Medical Marijuana Laws Reduce Prescription Medication Use In Medicare Part D. Health Aff 2016;35(7).

23. Center for Disease Control and Prevention. Analyzing prescription data and morphine milligram equivalents (MME). Available at https://www. cdc.gov/drugoverdose/resources/data.html. Accessed on Nov 11, 2019.

24. Iyengar et al. Dispensing Channel and Medication Adherence: Evidence Across 3 Therapy Classes. Am J Manag Care. 2013;19(10):798-804.

Publisher's Note: Springer Nature remains neutral with regard to jurisdictional claims in published maps and institutional affiliations. 